International Journal of Engineering \& Technology, $7(2.7)(2018) 722-724$
International Journal of Engineering \& Technology
Website: www.sciencepubco.com/index.php/IJET
Research Paper

\title{
Sub sampling based software GPS receiver
}

\author{
M Harshali ${ }^{1 *}$, M Venu Gopala Rao ${ }^{2}$ \\ ${ }^{1}$ SRF-CSIR, Dept. of ECE, KLE F, India \\ ${ }^{2}$ Professor, Dept. of ECE, KLE F, India \\ *Corresponding author E-mail: harshamane@kluniversity.in
}

\begin{abstract}
This paper focuses on reducing the processing time of software GPS receiver using sub-sampling techniques. As the GPS signals are wide band signals, sampling frequency is very high. Sub-sampling enables to reduce time for processing. From the simulation results, it is observed that the sampling frequency can be reduced up to $2.5 \mathrm{MHz}$ without loss of tracked signal. The processing time is reduced for software GPS receiver after sub-sampling. The overall reduction in processing time is from $3.456647 \mathrm{sec}$ to $2.15946 \mathrm{sec}$ respectively for sampling frequency $5 \mathrm{MHz}, 2.5 \mathrm{MHz}$. Thus time saved is $37 \%$ of the original one.
\end{abstract}

Keywords: Acquisition; GPS; Sub sampling; Software GPS receiver; Tracking.

\section{Introduction}

GPS is mainly designed for military application, mostly for navigation and mapping in order to compute positioning, velocity and time [1]. With rapid advances in Navigation, tremendous amount of progress has been done not only for positioning of civilian and military but also in other navigation, positioning and its related applications. GPS receiver has gained importance because of its flexibility [2]. Research in GPS receiver design growing faster every day with rapidly improved techniques. SGR reduces hardware implementation and supports to develop the design effectively [3]. Many researchers have worked on SGR design improvement, mainly on faster processing of reception of GPS signal. GPS receiver design consisting two parts named as hardware module and software module. The hardware front end module composed of path antenna followed by low noise amplifier and then the signal is down converted to IF frequency [4]. For further processing the signal is converted to digital with Analog to Digital Convertor (ADC) [5], [6]. The overall module referred as RF front end. In the software module Digital Signal Processor (DSP) processes the signal in order to track available satellite signal. Acquisition and tracking are main building of software module [7].

The acquisition and tracking find out visible satellites and demodulates the available satellite signal respectively [8]. For reduction of processing time of acquisition different techniques has been applied. Efforts has been taken by various techniques like Fast Fourier Transform (FFT), Discrete Fourier Transform (DFT), compressive acquisition, Sub-sampled fast fourier transform (ssFFT) to reduce acquisition time for GPS signal [9], [10], [11]. Sub-sampling is advantageous for wide band signals (like GPS) because of their sparse nature. It can be effectively done without loss of the important parameters of signal. ssFFT greatly reduces time for acquisition of satellites [9]. The author has sub-sampled the signal with different sampling frequencies varying from $11.999 \mathrm{MHz}$ to $1 \mathrm{MHz}$ [10]. Sub-sampling on tracking GPS sig- nal has also been done effectively with sampling $2.5 \mathrm{MHz}$ [12].The processing time can be reduced further after subsampling acquisition and tracking. This paper focuses on reduction of processing time combinedly on acquisition, pull in frequency as well as tracking with reduction of sampling frequency up to2.5 MHz.

This paper is organized as section II explains design of SGR. Section III gives detailed analysis and implementation of sub sampling in SGR. Section IV concludes this work.world growing faster every day with rapidly improved techniques[13-20].

\section{Sub-sampled SGR}

The basic building blocks of SGR are acquisition and tracking as illustrated in Fig.1. Correlating the incoming signal with the locally generated signal named as acquisition. whereas finding finest value of carrier frequency and code phase named as tracking.

To reduce processing time for these blocks one need to understand the exact working of these blocks and their significance. The basic function of each block is discussed below

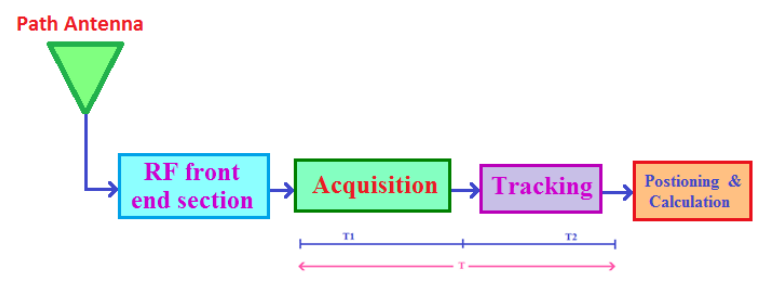

Fig. 1. Block diagram of GPS receiver 


\subsection{Acquisition}

One of the important task of GPS receiver is to achieve synchronisation of incoming signal to identify available satellite. It is two dimensional search operation, where the C/A code and Doppler shift are estimated coarsely. The correlation between incoming and locally generated signal produces spike at output.

\subsection{Tracking}

Tracking algorithm allows a GPS receiver to maintain lock on carrier frequency and C/A code of acquired signal so that receiver can determine the navigation observables and decode navigation data message. One necessary tracking algorithm is a delay-locked loop (DLL), which maintains phase alignment between the received C/A code and the replica generated at the receiver. The second one is a Phase-locked loop (PLL), which is used to track an incoming signal and to provide accurate measurements of phase and frequency of carrier. The processing time required for acquisition is $\mathrm{T} 2$.

\section{Results, Implementation \& Discussion}

For the implementing of proposed techniques real time data of satellite no 22 is used. Simulation work is carried out in Matlab version 2015. The similar inputs (data and locally generated PRN code of satellite no 22) have been given to these two blocks in Fig. 1 and sub-sampled with different sub-sampling frequency. The total processing time required is $\mathrm{T}$ means addition of $\mathrm{T} 1, \mathrm{~T} 2$. The sub-sampling applied on all three blocks with same or different sampling frequency as discussed below

The sub sampling frequency Fs=5MHz. The acquisition results obtained from simulations are as satellite number, $\mathrm{N}=22$ along with carrier frequency, $\mathrm{Fc}=1250500 \mathrm{MHz}$ and code phase delay 470. The time required for acquisition process, $\mathrm{T} 1$ is $0.102527 \mathrm{sec}$ Fig. 2 a represent the

The processing time for tracking of visible satellite signal is, $\mathrm{T} 2=3.456647$ sec. The Fig. $2 \mathrm{~b}$ represent the demodulated noisy signal.

Thus total time taken for complete process is $\mathrm{T}=\mathrm{T} 1+\mathrm{T} 2$ is $3.456647 \mathrm{sec}$

The sub sampling frequency Fs $=2.5 \mathrm{MHz}$. The acquisition results obtained from simulations are as satellite number, $\mathrm{N}=20$ along with carrier frequency, $\mathrm{Fc}=1249500 \mathrm{MHz}$ and code phase delay $236 * 2=472$. The time required for acquisition process, $\mathrm{T} 1$ is 0 . $0.045616 \mathrm{sec}$. Fig. 3a represent the acquisition of satellite signal.

The processing time for tracking of visible satellite signal is, $\mathrm{T} 2=2.113844 \mathrm{sec}$. The Fig. $3 \mathrm{~b}$ represent the demodulated noisy signal.

Thus total time taken for complete process is $\mathrm{T}=\mathrm{T} 1+\mathrm{T} 2$ is 2.15946 sec.

Table 1: Sub sampling simulation Results at different frequencies

\begin{tabular}{|l|l|l|l|l|}
\hline $\begin{array}{c}\text { Sr. } \\
\text { No }\end{array}$ & $\begin{array}{c}\text { Sampling } \\
\text { Frequency }\end{array}$ & $\begin{array}{c}\text { Acquisition } \\
\text { Results }\end{array}$ & $\begin{array}{c}\text { Tracking } \\
\text { Results }\end{array}$ & $\begin{array}{c}\text { Total Time } \\
\text { (Sec) }\end{array}$ \\
\hline & & $\begin{array}{l}\mathrm{N}=22 \\
\mathrm{Fc}=1250500 \\
\mathrm{Ph}=470\end{array}$ & $\mathrm{~T} 2=3.456647$ & $\mathrm{~T}=3.456647$ \\
1 & $\mathrm{Fs}=5 \mathrm{MHz} 1=0.102527$ & & \\
& & $\begin{array}{l}\mathrm{N}=20 \\
\mathrm{Fc}=1249500 \\
\mathrm{Ph}=236 * 2 \\
\mathrm{~T} 1=0.045616\end{array}$ & $\mathrm{~T} 2=2.113844$ & $\mathrm{~T}=2.15946$ \\
\hline & $\mathrm{Fs}=2.5 \mathrm{MHz}$ & & \\
\hline
\end{tabular}

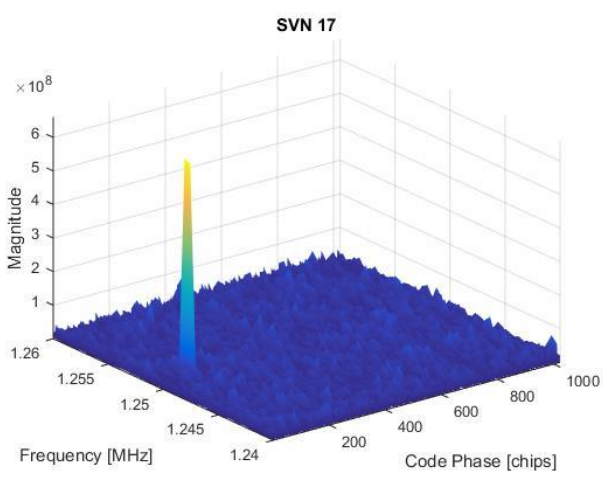

(a)

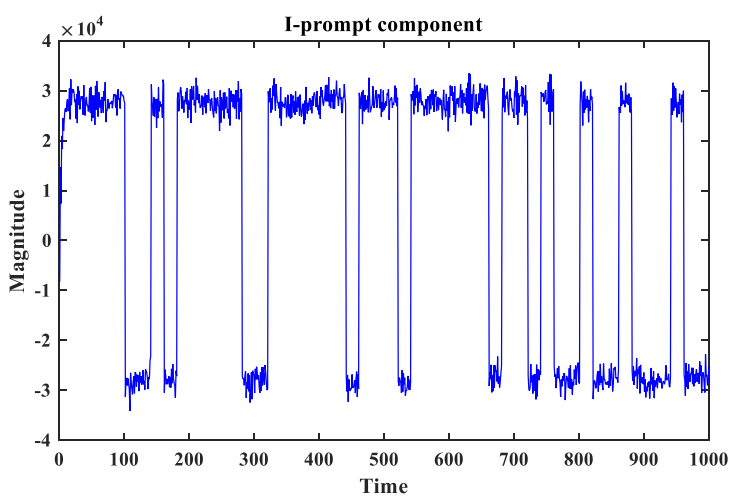

(b)

Fig. 2: Sub-sampling with sampling frequency $5 \mathrm{MHz}$

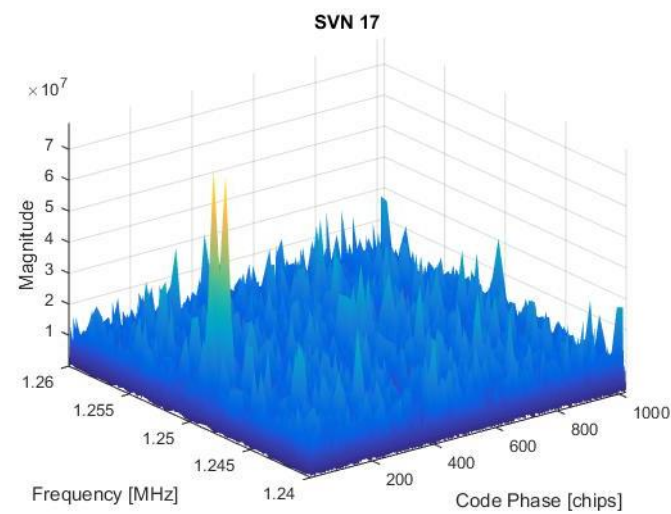

(a)

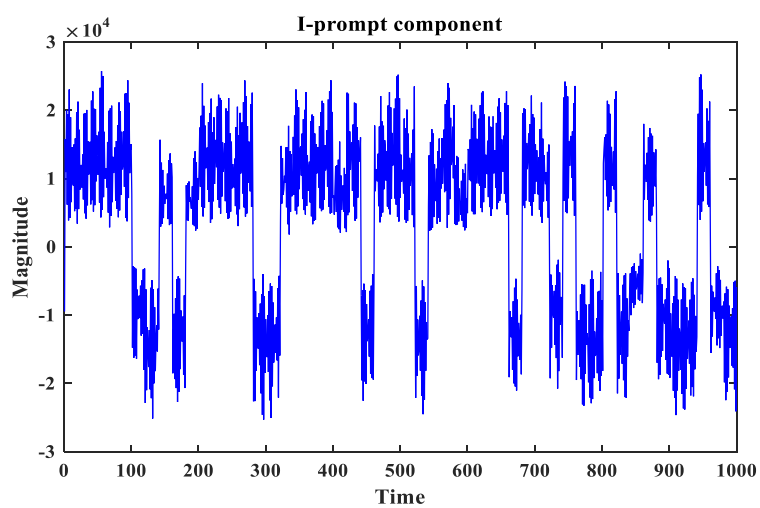

(b) 


\section{Conclusion}

This paper explore the sub sampled SGR to recover the demodulated signal with less tracking computation time and accuracy. Real time data of GPS satellite no 22 is simulated. From simulations, it is observed that combined sub-sampling of SGR results in accurate acquisition and tracking without loss of signal. The incoming signal is sub-sampled with sampling frequency $5 \mathrm{MHz}$ and $2.5 \mathrm{MHz}$ with the computation time $3.456647 \mathrm{sec}$ and $2.15946 \mathrm{sec}$ respectively. Thus time saved is $37 \%$ of the original one. Further efforts need to be taken in order to reduce overall computation time for processing of SGR.

\section{Acknowledgement}

I would like to express my deep gratitude towards the Council of Scientific and Industrial Research (CSIR), Government of India, for financial support in the form of Senior Research Fellowships (SRF). This work presented here is being carried out under the CSIR network project entitled as "Design of GPS based Software Defined Radio (SDR) using FPGA" with CSIR Sanction order No- 08/655(0001)/2017- EMR-I . I sincerely acknowledge my supervisor Dr. M Venu Gopala Rao for his guidance. I am grateful to the Department of ECE, K L University, Guntur for support and encouragement during this work.

\section{References}

[1] Kaplan E.D, Hegarty C, Understanding GPS Principles and Applications 2nd Ed. Artech House, 2005

[2] Tsui, J.B.Y, Fundamentals of Global Positioning System Receivers.

[3] A Software Approach, Copyright 2000 John Wiley and Sons, Inc.Print ISBN 0-471- 38154-3 Electronic ISBN 0-471- 20054-9.

[4] Tian, J., Ye, W., Lin, S., Hua, Z.:SDR GNSS Receiver Design over Stand-Alone Generic TI DSP platform.IEEE 10th Int. Symposium on SSTA, pp. 42-- 47,Bologna, 2008.

[5] Psiaki, M.L., "Block Acquisition of Weak GPS Signals in a Software Receiver," Proc. of ION GPS, Salt Lake City, UT, Sept. 11-14, 2001, pp. 2838-2850.

[6] Borre, K., Akos, D.M., Bertelsen, N., Rinder, P.Jensen, S.H.: A Software Defined GPS and Galileo receiver A Single-Frequency Approach, 1st edition, Boston, 2006.

[7] Miao, J., Chen, W., Liu, J., Sun, Y., Hu, C.: Design and implementation of GPS software receiver based on software-defined radio. Nanjing Hangkong Hangtian Daxue Xuebao/Journal of NUAA, vol. 40, no. 6, pp.774-779, 2008.

[8] Ratnam, D. V., Ashish, P., Swathi, P., Venu Gopala Rao, M. Acquisition of GPS L1 Signals using Cooley-Tukey FFT Algorithms, The 2013 IEEE International Conference on Signal Processing, Computing and Control (2013 IEEE ISPCC) at Jaypee University of Information Technology, Shimla, India from 26 28, September 2013.

[9] Venu Gopala Rao M., Ratnam, D. V., Faster GPS/IRNSS acquisition via sub sampled fast Fourier transform (ssFFT) and thresholding. Annual IEEE India Conference (INDICON), Mumbai, pp. 1-4, 2013.

[10] Venu Gopala Rao, M., Ratnam, D. V.: Faster Acquisition Technique for Software-defined GPS Receivers. Defence Science Journal, Vol. 65, No. 1, 2015.

[11] Harshali, M., Venu Gopala Rao, M.: Compressive Sampling on Speech Signal using Random Demodulator. International Journal of Applied Engineering Research, ISSN 0973-4562 Vol. 10 No.20, 2015.

[12] Harshali, M., Venu Gopala Rao, M.: Design of software design radio based GPS tracking using sub sampling. International Journal of Pure and Applied Mathematics, ISSN 1311-8080 (printed), ISSN 1314-3395 (online) Vol. 117, No.18, 2017, pp. 391-395

[13] MUDAVATH, M. and HARIKISHORE, K., 2016. Design of CMOS RF front-end of low noise amplifier for LTE system applications. Asian Journal of Information Technology, 15(20), pp. 4040-4047.
[14] HUSSAIN, S.N. and KISHORE, K.H., 2016. Computational Optimization of Placement and Routing using Genetic Algorithm. Indian Journal of Science and Technology, 9(47),

[15] KILARU, S., HARIKISHORE, K., SRAVANI, T., ANVESH CHOWDARY, L. and BALAJI, T., 2014. Review and analysis of promising technologies with respect to Fifth generation networks, 1st International Conference on Networks and Soft Computing, ICNSC 2014 - Proceedings 2014, pp. 248-251.

[16] MADHAV, B.T.P., PISIPATI, V.G.K.M., KHAN, H. and UJWALA, D., 2014. Fractal shaped Sierpinski on EBG structured ground plane. Leonardo Electronic Journal of Practices and Technologies, 13(25), pp. 26-35

[17] SUBBARAO, G.V. and MULAVEESALA, R., 2012. Quadratic frequency modulated thermal wave imaging for non-destructive testing. Progress In Electromagnetics Research M, 26, pp. 11-22.

[18] MADHAV, B.T.P., KRISHNAM NAIDU YEDLA, G.S., KUMAR, K.V.V., RAHUL, R. and SRIKANTH, V., 2014. Fractal aperture EBG ground structured dual band planar slot antenna. International Journal of Applied Engineering Research, 9(5), pp. 515-524.

[19] MADHAV, B.T.P., MOHAN REDDY, S.S., SANJAY, B. and UJWALA, D., 2013. Trident shaped ultra wideband antenna analysis based on substrate permittivity. International Journal of Applied Engineering Research, 8(12), pp. 1355-1361.

[20] MADHAV, B.T.P., MANIKANTA PRASANTH, A., PRASANTH, S., KRISHNA, B.M.S., MANIKANTHA, D. and NAGASAI, U.S., 2015. Analysis of defected ground structure notched monopole antenna. ARPN Journal of Engineering and Applied Sciences, 10(2), pp. 747-752. 